\title{
A Novel Triple-Band Microstrip-Fed Meandered Monopole antenna with Defected Ground Structure
}

\author{
Ranjit Singh Momi ${ }^{1}$, Rajni ${ }^{2}$ \\ ${ }^{1}$ (ECE, SBSSTC/ PTU, India) \\ ${ }^{2}(E C E, S B S S T C / P T U$, India $)$
}

\begin{abstract}
A novel triple-band Defected Ground Structured (DGS) meandered monopole antenna is presented in this paper. In the proposed antenna, three vertical and one horizontal protrudent strips are employed onto ground plane to increase the bandwidth. High Frequency Structure Simulator (HFSS) software based on Finite Element Method (FEM) is used to attain the performance parameters of proposed antenna. The simulated results of triple-band proposed antenna cover the required bandwidths of the PCS-1900/UMTS-2100 and the 2.4/5.2/5.8 GHz WLAN standards.
\end{abstract}

Keywords: Microstrip Patch Antenna (MPA), Defected Ground Structure (DGS), Triple Band, Peak Gain and Peak Directivity, Bandwidth (B.W.), Return Loss ( ${ }_{11}$ ), Voltage Standing Wave Ratio (VSWR).

\section{Introduction}

The many favorable features that planar monopole antennas exhibit, including a wide bandwidth, good radiation properties, low cost and simple fabrication have resulted in significant research conducted in this field. Traditional monopole antenna is inherently a narrowband configuration. As reported in [1], a simple microstrip stub served as the impedance matching element and provided around $13 \%$ bandwidth improvement when get compared with the traditional design. Several monopole designs have been studied employing various ground planes of dissimilar shapes so that the impedance bandwidth can be enhanced [2-4]. A number of designs have been used to reduce size of MPA which includes the implementation of planar inverted F antenna (PIFA) or substrate with high dielectric constant. Recent research of Electromagnetic Band gap (EBG) has led to an immense research interest including antenna performance improvements of size reduction [5-6], gain enhancement [7] and radiation efficiency improvement [8] and so forth. A remarkable category of EBG structures named Defected Ground Structure (DGS) is invented recently which has a controllable finite transmission zero characteristic [9]. Defected ground structure (DGS) method is also used for size reduction as well as multi-band operations [10] which stimulate additional resonance modes [11-14]. As compare to Photonic Band Gap (PBG) surfaces, defected ground structure (DGS) has gained noteworthy interests. This is because of the fact that DGS has been designed to diminish certain frequency bands, and for this reason these are sometimes also known as Electromagnetic Band-Gap (EBG) structures. DGS has uncomplicated configuration and have potential applications in microwave circuit's designs including filters, amplifiers and oscillators [15].

A simple triple-band design of the microstrip-fed monopole antenna consisting of a meandered-strip element and a ground plane with three shorted parasitic strips is being presented in this paper. This refers to the works reported in [16-18] showing that a microstrip-fed monopole antenna with a shorted parasitic strip can excite both dual and broadband operation respectively. Good triple-broad impedance bandwidths as well as radiation characteristics which are appropriate for multi-band wireless communication systems can be achieved by properly adding strips to the ground and carefully selecting the positions and lengths of these strips. The wireless communication systems include Personal Communication System (PCS)-1900, Universal Mobile Telecommunication System (UMTS)-2100 and 2.4/5.2/5.8 GHz IEEE 802.11 Wireless Local Area Network (WLAN) operations. Comparison between reference antenna [19] and proposed antenna have been presented and simulated in terms of Return Loss, Bandwidth, VSWR, Peak Gain, Peak Directivity and Radiation Pattern over three operating bands.

This paper is organized in four sections. First section provides introduction regarding Microstrip Patch Antenna (MPA) with DGS. In second section, structure of the proposed antenna and reference antenna is discussed which includes its dimensions and material used. In third section, simulation results of both antennas have been presented in terms of Return Loss $\left(\mathrm{S}_{11}\right)$, Bandwidth, VSWR, Peak Gain, Peak Directivity and Radiation Pattern. The last section concludes the paper mentioning the advantages and application of the proposed antenna.

\section{Antenna Design}

Both reference and proposed meandered monopole antennas for triple-band operation are etched on a single side of an FR4 epoxy substrate having dimensions $35 \times 48 \mathrm{~mm}^{2}$ with relative permittivity $\left(\varepsilon_{\mathrm{r}}\right)$ of 4.2 and 
substrate thickness $1.6 \mathrm{~mm}$. It consists of a radiating meandered strip and a ground plane on another side of the substrate. The schematic configuration of triple-band reference meandered monopole antenna with Defected Ground Structure (DGS) is shown in Fig. 1. The meandered shaped radiating patch is fed by $50 \Omega$ microstrip line with width $3 \mathrm{~mm}$ and length $18 \mathrm{~mm}$. The total length of microstrip line feed including meandered patch is about $37.5 \mathrm{~mm}$. To reduce the height of antenna and hence, miniaturizing the overall size of antenna, the central part of the monopole strip at a distance of $7 \mathrm{~mm}$ from the top edge of the ground plane was meandered to form a hook. This formed hook is configured with horizontal as well as vertical section having lengths of $6 \mathrm{~mm}$ and 7.5 mm, respectively.

The ground plane is selected to be $35 \times 18 \mathrm{~mm}^{2}$ with three protrudent strips that have been employed and short-circuited to the same ground plane. These shorted protrudent strips, denoted as strips 1, 2 and 3 are introduced to improve excitation of the resonant modes for this antenna. The central line of the ground (in zdirection) is positioned with $1.5 \mathrm{~mm}$ offset with respect to the microstrip feed line. The position of strip 1 is 6.5 $\mathrm{mm}$ to the left edge of the ground plane, while that for strip 3 is $5.5 \mathrm{~mm}$ to the ground's right edge. As for strip 2 , it is optimally sited between strips 1 and 3 with a distance of $3.5 \mathrm{~mm}$ from strip 3. Such an arrangement of addition of three shorted parasitic strips show outcome in different electromagnetic coupling effects between the meandered monopole and these strips. This can effectively increase the resonances and attain better resonant frequencies as well as impedance bandwidths.

Finally, the optimal lengths for strips 1,2 and 3 are 6,6 and $29 \mathrm{~mm}$, respectively. It should be noted that although the selected length of $29 \mathrm{~mm}$ for strip 3 increases the overall size of the proposed meandered monopole antenna. And, the lowest resonant mode can be generated at a frequency as low as $1.9 \mathrm{GHz}$ which in general desires a current length of about $42 \mathrm{~mm}$, estimated from the one-quarter wavelength rule in free space at resonance.

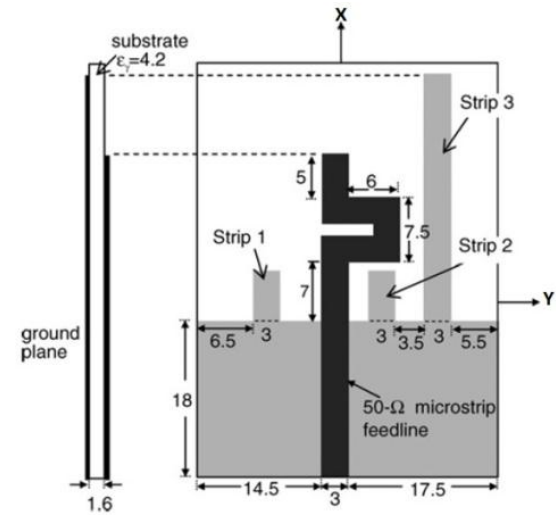

Fig. 1: Schematic configuration of reference antenna

The proposed antenna is fabricated by doing amendments in reference antenna. All the design parameters of proposed antenna are similar to reference antenna except two edges having dimensions of $2 \times 2$ $\mathrm{mm}^{2}$ which are protruded on the both sides of left most strip of ground plane. These protruded edges along left most strip of ground helps to improve Bandwidth and Return Loss etc. without degrading other antenna performance parameters. The schematic configuration of the proposed meandered monopole antenna with Defected Ground Structure (DGS) for triple-band operation is shown in Fig. 2.

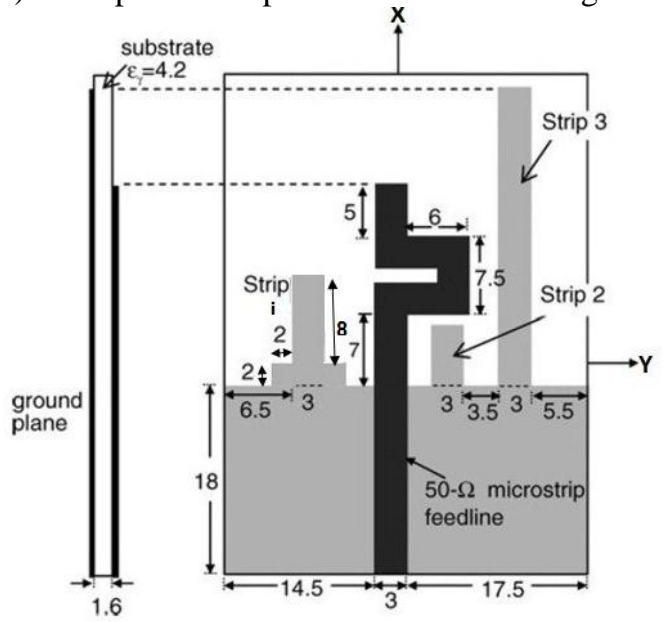

Fig. 2: Schematic configuration of proposed antenna 
The complete geometry of the proposed meandered monopole antenna with Defected Ground Structure (DGS) modeled in HFSS environment is shown in Fig. 3. HFSS is a high-performance full-wave electromagnetic (EM) field simulator for arbitrary 3D volumetric passive device modeling which takes advantage of the familiar Microsoft Windows graphical user interface.

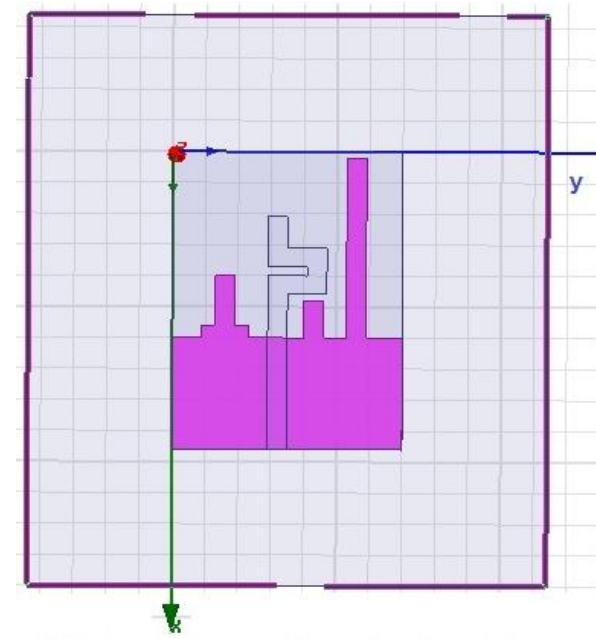

Fig. 3: Proposed model of meandered monopole antenna with DGS

\section{Simulation Results and Discussion}

After modeling the proposed geometry of model in HFSS, the model is assigned suitable boundary conditions for far-field calculation. Then adaptive meshing of problem domain including boundary is employed. In adaptive meshing, the mesh is refined for each iteration, a full solution is performed and the process is repeated to give the most accurate results possible until convergence.

\section{a. Return Loss $\left(\mathrm{S}_{11}\right)$ and Bandwidth}

The simulated return loss $\left(S_{11}\right)$ of the reference antenna is shown In Fig. 4. The results show that reference antenna operate at three resonant bands at frequencies of $1.92,5.19$ and $5.77 \mathrm{GHz}$ with impedance bandwidths of about $956.6 \mathrm{MHz}(1.7635-2.7201 \mathrm{GHz}), 945.1 \mathrm{MHz}(4.4511-5.3962 \mathrm{GHz})$ and $550.5 \mathrm{MHz}$ (5.5226-6.0731 GHz) respectively.

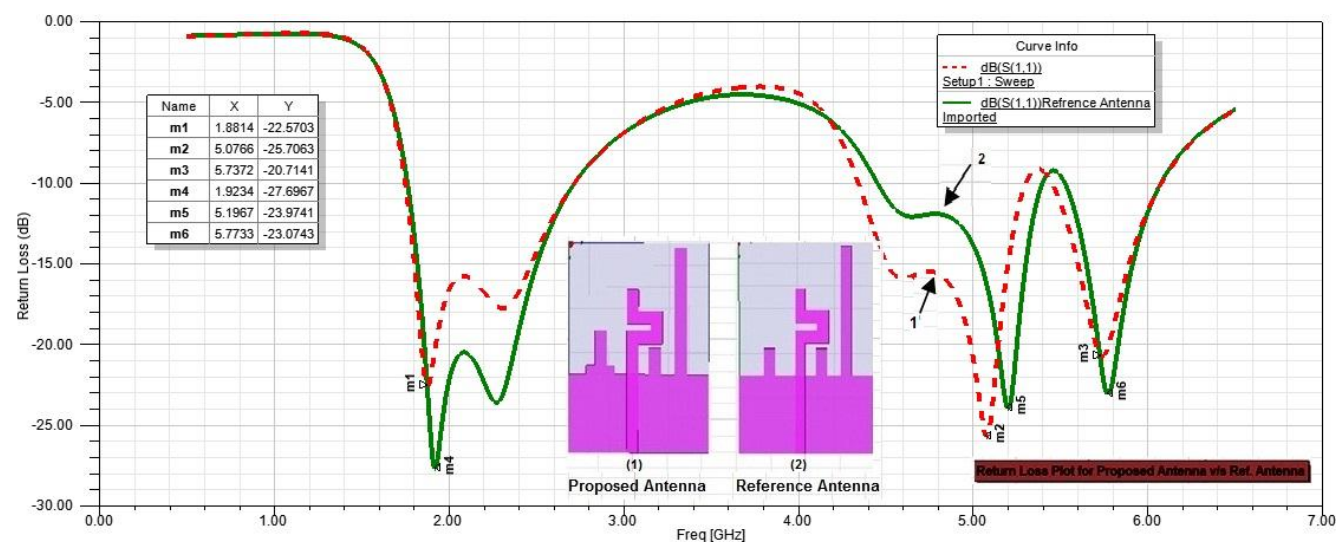

Fig. 4: Simulated $S_{11}$ v/s frequency plot for proposed and reference antennas

Two protrudent edges on the both sides of ground plane along the left most strip, helps to increase the path of current which further helps to improve Bandwidth, Return Loss etc. for the proposed model. Apparently, the simulation results reveal three resonant bands at frequencies of $1.88,5.07$ and $5.73 \mathrm{GHz}$ with impedance bandwidths of about $968.8 \mathrm{MHz}(1.7517-2.7204 \mathrm{GHz}), 958.1 \mathrm{MHz}(4.3421-5.3002 \mathrm{GHz})$ and $626.8 \mathrm{MHz}$ (5.4491-6.0759 GHz) respectively.

Therefore, it is concluded that the bandwidth of all three operating bands get enhanced with proposed antenna than that of reference antenna by $12.1 \mathrm{MHz}, 13.0 \mathrm{MHz}$ and $76.3 \mathrm{MHz}$ respectively. Also the above obtained bandwidths simultaneously cover the Personal Communication System (PCS 1850-1990MHz), 
Universal Mobile Telecommunication System (UMTS 1920-2170MHz), Bluetooth (2.4-2.5 GHz) and Wireless Local Area Network (WLAN 2.4/5.2/5.8 GHz) bands.

\section{b. Voltage Standing Wave Ratio (VSWR)}

Fig. 5 shows VSWR plot of the reference and proposed meandered monopole antenna with Defected Ground Structure (DGS). For proposed antenna, the simulated values of VSWR at three resonance frequencies are 1.16, 1.10 and 1.20 respectively. In case of reference antenna, the simulated values of VSWR at three resonance frequencies are 1.08, 1.13 and 1.15 respectively as shown in Fig. 5. For both antennas, the value of VSWR at three resonance frequencies is approximately equal to 1 which helps in perfect impedance matching.

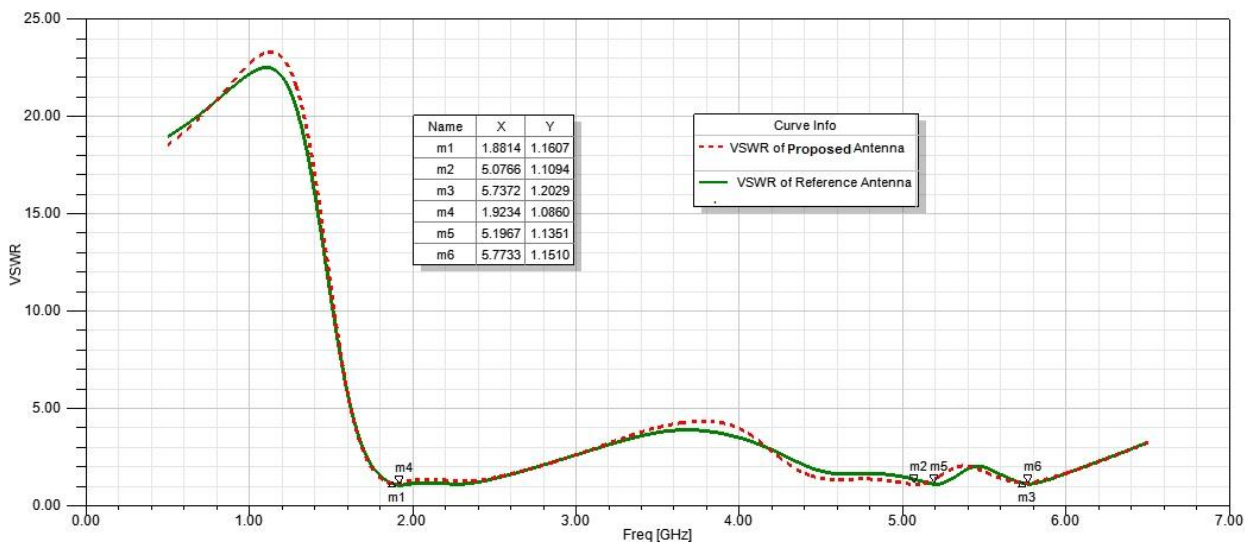

Fig. 5: Simulated VSWR v/s frequency plot for proposed and reference antennas

\section{c. Peak Gain}

The peak gain of the proposed and reference antenna design for frequencies across the triple operating bands is shown in Fig. 6. For proposed antenna, the simulated peak gains across triple operating bands are about $2.50,4.56$ and $4.12 \mathrm{~dB}$ respectively; while the simulated peak gains of reference antenna for triple operating bands are about $2.6703,4.7692$ and $5.4284 \mathrm{~dB}$ respectively.

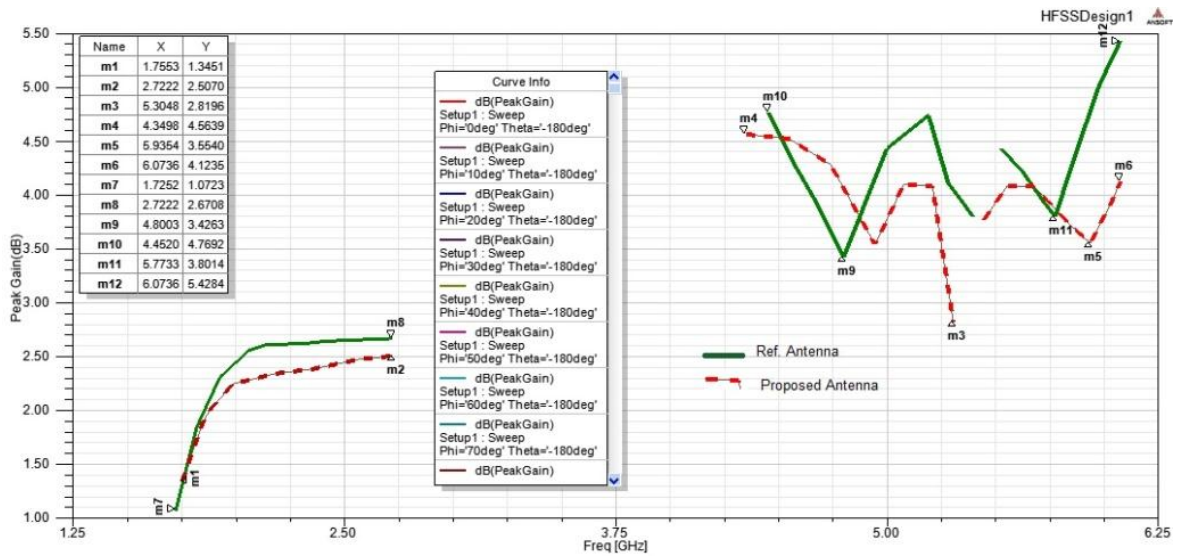

Fig. 6: Simulated peak gain v/s frequency plot for proposed and reference antennas

\section{d. Peak Directivity}

The peak directivity of the proposed and reference antenna design for frequencies across the triple operating bands are shown in Fig. 7. For proposed antenna, the simulated peak directivity across triple operating bands are about $2.99,5.15$ and $4.25 \mathrm{~dB}$ respectively, while simulated peak directivity of reference antenna across triple operating bands are about 3.04, 5.23 and $5.32 \mathrm{~dB}$ respectively. 


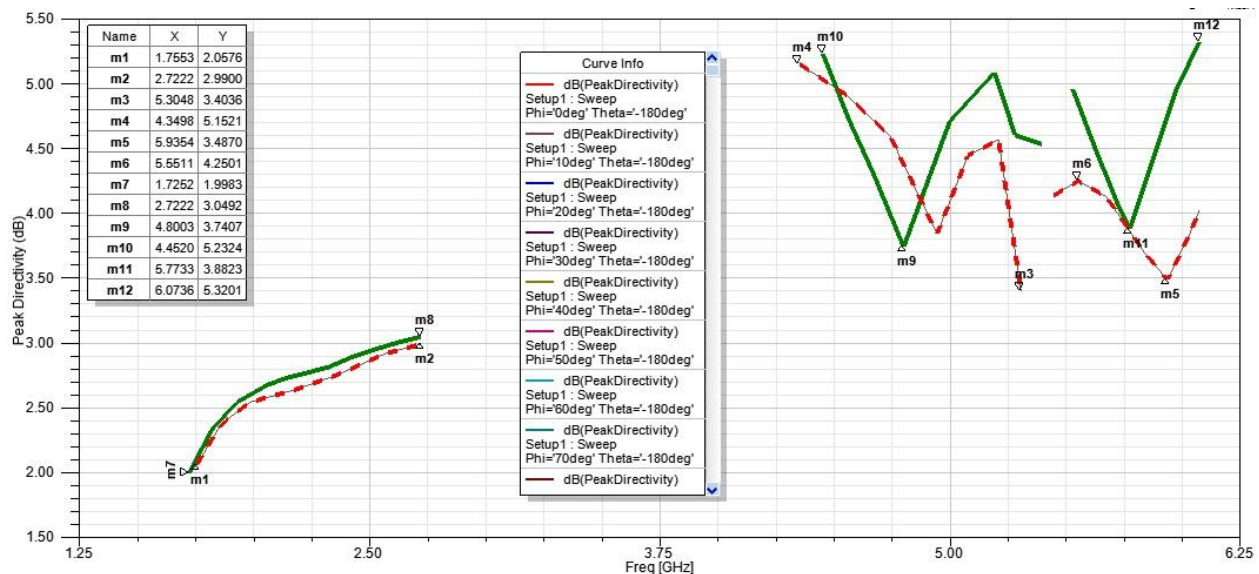

Fig. 7: Simulated peak directivity v/s frequency plot for proposed and reference antennas

\section{e. Radiation Pattern}

Fig. 8 (1), 8 (2) and 8 (3) show the simulated radiation patterns of proposed antenna for $x-y, y-z$ and $z-$ x plane when operating at $1.88 \mathrm{GHz}$ respectively. Fig. $9(1), 9(2)$ and $9(3)$ reveal the simulated radiation patterns of proposed antenna for $x-y, y-z$ and $z-x$ plane when operating at $5.07 \mathrm{GHz}$ respectively. Fig. 10 (1), 10 (2) and 10 (3) present the simulated radiation patterns of proposed antenna for $x-y, y-z$ and $z-x$ plane when operating at $5.73 \mathrm{GHz}$ respectively for Personal Communication System (PCS)-1900, Universal Mobile Telecommunication System (UMTS)-2100 and 2.4/5.2/5.8 GHz IEEE 802.11 Wireless Local Area Network (WLAN) applications.

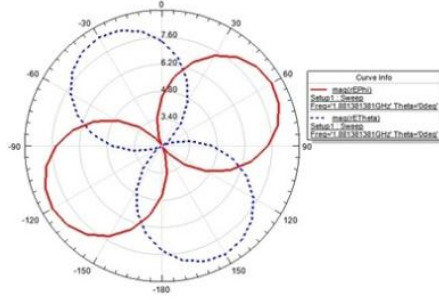

(1)

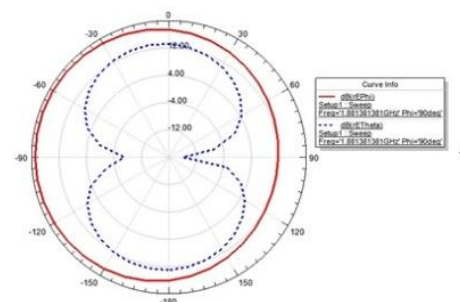

(2)

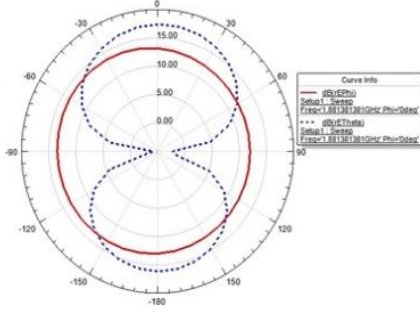

Fig. 8: Simulated radiation pattern for proposed antenna at $1.88 \mathrm{GHz}$ for (a) $x-y$ plane (b) y-z plane (c) z$x$ plane

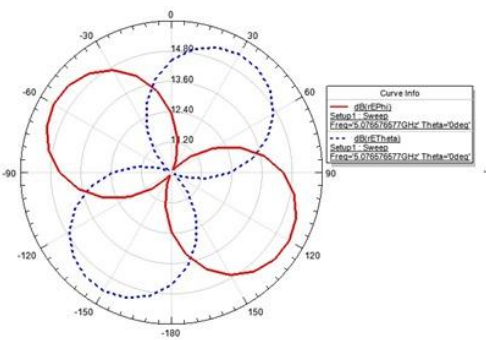

(1)

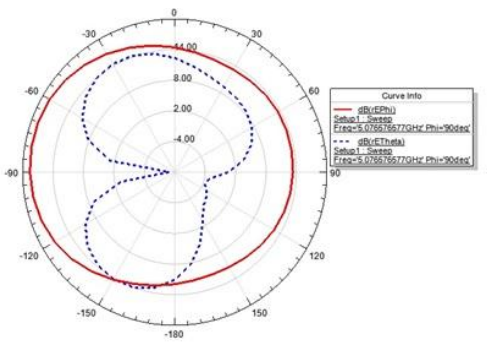

(2)

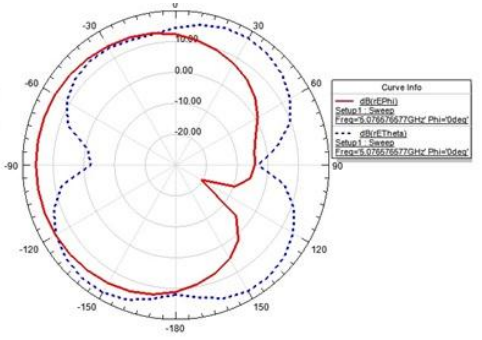

(3)

Fig. 9: Simulated radiation pattern for proposed antenna at $5.07 \mathrm{GHz}$ for (a) $x-y$ plane (b) $y-z$ plane (c) zx plane

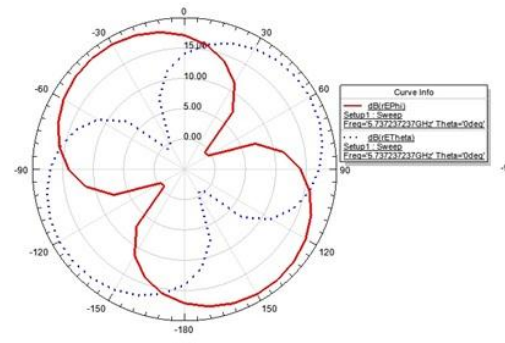

(1)

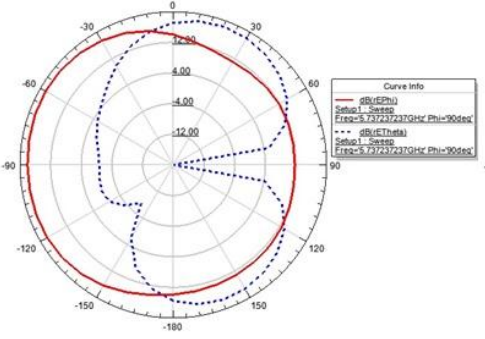

(2)

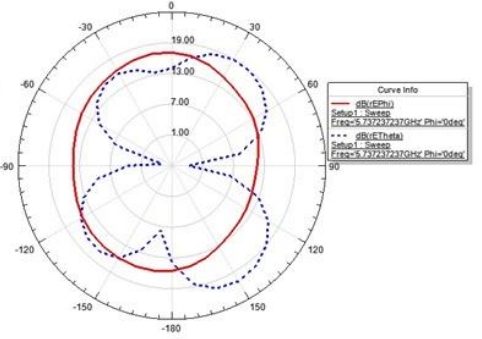

(3)

Fig. 10: Simulated radiation pattern for proposed antenna at $5.73 \mathrm{GHz}$ for (a) $x-y$ plane (b) $y-z$ plane (c) z-x plane 


\section{Conclusion}

A new microstrip-fed antenna design based on the meandered monopole for a triple-frequency operation has been proposed with simulated results. For the monopole structure, the ground plane with three parasitic strips assists the proposed antenna to excite triple-resonances and has a suitable radiation performance to cater for the triple-frequency wireless systems. This includes PCS- 1900/UMTS-2100 and 2.4/5.2/5.8 GHz WLAN frequency bands. The bandwidth of all three operating bands gets enhanced by proposed antenna than reference antenna by $12.1 \mathrm{MHz}, 13.0 \mathrm{MHz}$ and $76.3 \mathrm{MHz}$ respectively. In addition to this, the proposed antenna has good Peak Gain and Peak Directivity across three operating bands as compared to reference antenna.

\section{References}

[1]. D. M. Pozar and B. Kaufman, "Increasing the bandwidth of a microstrip antenna by proximity coupling," Electron. Lett., vol. 23, pp. 368-369, Apr. 1987.

[2]. Singh, Gurpreet, and Ranjit Singh Momi. "Micro strip Patch Antenna with Defected Ground Structure for Bandwidth Enhancement." International Journal of Computer Applications 73 (2013).

[3]. $\quad$ Singh, Gurpreet, and Anupma Marwaha. "Design of G-Shaped Defected Ground Structure for Bandwidth Enhancement." International Journal of Computer Applications 75 (2013).

[4]. M. J. Ammann and Z. N. Chen, "Wideband monopole antennas for multi-band wireless systems," IEEE Antennas Propag. Mag., vol. 45, no. 4, pp. 146-150, Apr. 2003.

[5]. J. S. Lim, J. S. Park, Y. T. Lee, D. Ahn, and S. W. Nam, "Application of defected ground structure in reducing the size of amplifiers,” IEEE Microw. Wireless Compon. Lett., vol. 12, pp. 261 263, Jul. 2002.

[6]. Y. J. Sung, C. S. Ahn, and Y. S. Kim, "Size reduction and harmonic suppression of rat-race hybrid coupler using defected ground structure," IEEE Microw. Wireless Compon. Lett., vol. 14, pp. 7-9, Jan. 2004.

[7]. J. S. Kuo and G. B. Hsieh, "Gain enhancement of a circularly polarized equilateral-triangular microstrip antenna with a slotted ground plane,” IEEE Trans. AntennasWireless Propag., vol. 51, no. 7, pp. 1652-1656, Jul. 2003.

[8]. C. J. Wang and W. T. Tsai, "A slot antenna module for switchable radiation patterns," IEEE Antennas Wireless Propag. Lett., vol. 4, pp. 202-204, 2005.

[9]. D. Ahn, J. S. Park, C. S. Kim, J. Kim, Y. X. Qian, and T. Itoh, "A design of the low-pass filter using the novel microstrip defected ground structure,” IEEE Trans. Microw. Theory Tech., vol. 49, no. 1, pp. 86-93, Jan. 2001.

[10]. Dalia Nashaat, Hala Elsadek and Hani Ghali "Multiband Miniaturized PIFA for Compact Wireless Communication Applications," published in Microwave antenna Optical Technology letters vol. 42, No.3, PP. 230-235, August 2004.

[11]. J. P. Thakur and J. S. Park, "An advance design approach for circular polarization of the microstrip antenna with unbalance DGS feedlines,” IEEE Antennas Wirel. Propag. Lett., vol. 5, no. 1, pp. 101-103, 2006.

[12]. M. A. Antoniades and G. V. Eleftheriades, "A compact multiband monopole antenna with a defected ground plane," IEEE Antennas Wirel. Propag. Lett., vol. 7, pp. 652-655, 2008.

[13]. K. H. Chiang and K. W. Tam, "Microstrip monopole mntenna with enhanced bandwidth using defected ground structure," IEEE Antennas Wirel. Propag. Lett., vol. 7, pp. 532-535, 2008.

[14]. D. Nashaat, H. A. Elsadek, E. Abdallah, H. Elhenawy, and M. F. Iskander, "Multiband and miniaturized inset feed microstrip patch antenna using multiple spiral-shaped defect ground structure (DGS)," in Proc. IEEE AP-S Int. Symp., Jun. 2009, pp. 1-4.

[15]. Chung, Y., S.-S. Jeon, S. Kim, D. Ahn, J.-1. Choi, and T. Itoh, "Multifunctional microstrip transmission lines integrated with defected ground structure for RF front-end application," IEEE Transactions on Microwave Theory and Techniques, Vol. 52, No.5, 1425-1432, May 2004

[16]. Jan J.Y., Tseng L.C., "Small planar monopole antenna with a shorted parasitic inverted-L wire for wireless communications in the 2.4-, 5.2-, and 5.8-GHz bands", IEEE Trans. Antennas Propag., 2004, 52, (7), pp. 1903-1905.

[17]. Huang C.Y., Chiu P.Y., "Dual-band monopole antenna with shorted parasitic element”, Electron. Lett., 2005, 41, (21), pp. 11541155 .

[18]. Joseph M., Raj R.K., Suma M.N., Mohanan P., “Compact dual-band antenna for DCS/2.5 GHz WLAN applications,” Microw. Opt. Technol. Lett., 2006, 48, (5), pp. 856-859.

[19]. W. C. Liu, M. Ghavami, and W. C. Chung, "Triple-frequency meandered monopole antenna with shorted parasitic strips for wireless application,” IET Microw. Antennas Propag., vol. 3, no. 7, pp. 1110-1117, 2009. 